\title{
LA YUGOSLAVIA DE TITO. EL FRACASO DE UN ESTADO MULTINACIONAL
}

\author{
Marina Casanova
}

\begin{abstract}
RESUMEN.
Al término de la ll Guerra mundial, Tito tuvo la oportunidad de construir gracias a la revolución comunista, un nuevo sistema político, una ideología universal y un Estado multiétnico. Sin embargo, ni el federalismo, ni el sistema de autogestión, ni el movimiento de países no-alineados fueron suficientes para mantener un Estado basado en la propia personalidad de Tito y en el monopolio de la burocracia de la Liga de Comunistas de Yugoslavia. El Titismo no pudo sobrevivir a Tito.
\end{abstract}

\section{PALABRAS CLAVES}

Titismo. Autogestión. No-alineados. Comunismo. Multiétnico. Yugoslavia.

\begin{abstract}
.
After the II World War, Tito established in Yugoslavia, through the communist revolution, a new political system, a world-wide ideology and a multiethnic State. However, nor the federalism, neither the self-management or the nonaligned movement had strength enough to keep going a State based on Tito's own personality and the monopoly of the communist party. Titoism system could not survive after Tito's death.
\end{abstract}

\section{KEYWORDS.}

Titoism. Self-management. Communism. Multiethnic. Nonaligned movement. Yugoslavia.

La Yugoslavia de Tito fue un claro ejemplo de un Estado compuesto por diversas nacionalidades. Se ha dicho que Yugoslavia no fue un país, sino un laboratorio. En los años noventa explotaron los alambiques debido a la incapacidad del sistema para crear una única nacionalidad: el yugoslavismo.

Para entender la II Yugoslavia es necesario considerarla por lo que fue: un campo de batalla entre una visión nacionalista unitaria, y otra basada en los particularismos de las diferentes repúblicas.

Sería un error creer que la muerte de Tito en 1980 fue el inicio de la desintegración de Yugoslavia. Las contradicciones del sistema empezaron mucho antes. Yugoslavia atravesó a lo largo de su historia dos etapas claramente diferenciadas: una primera desde su creación en 1918 hasta 1941, y una segunda a partir de 1945: la Yugoslavia de Tito. 
La II Yugoslavia fue creada durante la ocupación extranjera y al tiempo que se desarrollaba una guerra civil con matices religiosos. Representaba un intento revolucionario para poner fin a la frágil integración civil y social de sus habitantes y construir una sociedad socialista, primero a la manera ortodoxa estalinista, y más tarde a través de sistema «autogestionario». El Reino de Serbios, Croatas y Eslovenos creado en 1918 al término de la I Guerra mundial, representó la materialización histórica de un ideal forjado en el siglo XIX, el yugoslavismo que uniría a todos los Eslavos del Sur que poseían una cultura común. Así lo imaginaron sus promotores, pero no quiere decir que lo lograran. El nuevo Estado que en 1926 tomaría el nombre de Yugoslavia, era una mezcla de pueblos con culturas y religiones diferentes, herencia de la división de la Cristiandad entre Católicos y Ortodoxos, y después de la invasión de los turcos en el siglo XV, la llegada del islamismo. La cuestión nacional impregnó todos los aspectos de la vida desde 1918 hasta 1980.

El desarrollo de las identidades nacionales fue paralelo al de los mitos históricos. Los Croatas se remontaban a su reino medieval del siglo X, y esperaban volver a construir un Estado independiente. Los Serbios nunca olvidaron su derrota ante los turcos el 28 de junio de 1389, en la batalla de Kosovo Poljie. Por su parte, los eslavos islamizados conservaron la lengua serbo-croata, pero no se consideraban ni serbios ni croatas. Todos ellos crearon costumbres, ritos y creencias diferentes que fueron moldeando los sentimientos nacionalistas.

En abril de 1941, después de su derrota militar ante los ejércitos alemanes, Yugoslavia dejó de existir como Estado. Los Ustaše del nuevo Estado Independiente de Croacia creado por los alemanes y liderado por Ante Pavolic, iniciaron las masacres contra los serbios asentados en Croacia, a los que consideraban invasores como lo fueron en el pasado húngaros y austriacos.

En el complicado mosaico de nacionalidades es difícil entender el inicio de la insurrección. En el Estado Independiente de Croacia, los serbios Cetnici, término que define a las bandas armadas que lucharon contra los turcos, se alzaron en defensa propia contra los croatas extremistas y los musulmanes «por el rey, la patria y la religión». En Serbia se alzaron contra los alemanes y más tarde lo harían contra los comunistas, a los que consideraban responsables de las represalias de los alemanes, lo que originó que en ocasiones actuaran en connivencia con ellos.

Los partisanos, principalmente serbios del oeste y montenegrinos comunistas, se levantaron en Montenegro contra las fuerzas de ocupación, pero pronto se dieron cuenta de que la única manera de hacerse con el poder, era terminar con las rivalidades entre las diferentes nacionalidades. Su lucha se basaba en un movimiento patriótico sin distinción de nacionalidades para liberar al país de la ocupación extranjera e imponer una sociedad más igualitaria. 
Divididos en comunistas y anticomunistas, Cetnici y Ustaše, lucharon todos contra todos para lograr sus objetivos: restablecer el Estado y obtener el poder al término de la guerra.

Al término de la guerra, Tito controlaba todo el aparato militar y político e impulsó la creación de un Frente Popular que, en las elecciones del 11 de noviembre, obtuvo el $90,48 \%$ de los votos. El 29 de noviembre de 1945 se proclamó la República Federal Popular Democrática de Yugoslavia, controlada por el partido comunista que, en 1954 tomaría el nombre de Liga de los Comunistas. A diferencia de otras Repúblicas de Europa del este, los comunistas yugoslavos fueron los que liberaron el país y esto dio a sus dirigentes una gran libertad de acción. Por otro lado, como consecuencia de la guerra civil y de la represión realizada durante y después de la guerra, Tito no encontró oposición para aplicar el modelo soviético en la nueva Yugoslavia. Para ello tuvo que crear nuevas formas de funcionamiento que quedaron reflejadas en la Constitución de 1946.

Siguiendo el modelo soviético, la Constitución de 1946 aparece como una de las más democráticas, instaurando el federalismo, el bicameralismo, la dirección colegiada del Estado y la proclamación de amplios derechos de los ciudadanos. Pero en realidad se trataba de la imposición de un partido único liderado por Tito.

La nueva Yugoslavia estaba formada por seis repúblicas federadas, Croacia, Serbia, Eslovenia, Bosnia-Herzegovina, Montenegro, Macedonia y las regiones autónomas de Kosovo y la Voivodina. Los derechos de cada una de las repúblicas estaban supeditados a los de la República federal y, aunque en la Constitución de 1946 el término federal presuponía la autodeterminación de las repúblicas federadas, en la práctica ese derecho sólo se aplicó a la independencia cultural y económica, puesto que, como señaló Tito, ya habían ejercido su derecho cuando se unieron en un Estado federal. Por otro lado, las fronteras que delimitaba las repúblicas no coincidían con las fronteras entre los diferentes pueblos. Exceptuando Eslovenia, las restantes repúblicas estaban habitadas por diferentes pueblos y nacionalidades.

La Constitución de 1946 hizo una distinción fundamental entre "pueblos» y "nacionalidades". Los "pueblos" son los constitutivos de la Federación yugoslava y disponen de "hogares nacionales" como es el caso de los eslovenos, los croatas, los serbios, los montenegrinos y los macedonios. Todos ellos forman parte de los Eslavos del Sur y no poseen un Estado nación de referencia fuera de la Federación. El reconocimiento de «pueblo» para los macedonios se explica por el peso histórico de la cuestión macedonia, y en el caso de los montenegrinos, a pesar de su escasa importancia numérica, por su participación masiva en las fuerzas partisanas. La categoría de «pueblo» va unida a la identidad personal y no a la colectiva o territorial. Por ejemplo, los Croatas tienen dos «hogares 
nacionales», en Croacia y en Bosnia. Los serbios son considerados como "pueblo» en Serbia, Croacia, Montenegro, Macedonia y Bosnia.

Por el contrario, otros grupos también numerosos sólo constituían «nacionalidades», como los italianos de Istria, los húngaros de la Voivodina y los albaneses de Serbia, Bosnia, Macedonia, Kosovo y Montenegro, porque disponían de un Estado nación fuera de la Federación y, en consecuencia no podían constituirse en repúblicas federadas. Por último, todo los «pueblos»y "nacionalidades» poseen la ciudadanía federal, la yugoslava.

A las seis Repúblicas, dos provincias autónomas y cinco naciones citadas, hay que añadir que se hablaban tres lenguas, el serbocroata, el esloveno y el macedonio; había tres religiones, la ortodoxa, la católica y la musulmana y dos alfabetos, el latino y el cirílico. En este rompecabezas imposible, Tito persiguió un único objetivo: convivir en unidad y fraternidad.

Hasta 1949, el modelo económico estuvo condicionado a la evolución política del régimen. Siguiendo el modelo soviético, se establecieron planes quinquenales privilegiando la industria pesada. Sin embargo, las repúblicas más subdesarrolladas nunca llegaron a cumplir los objetivos propuestos. El modelo soviético también se aplicó a la agricultura, reforma agraria, colectivizaciones forzosas, control de precios, medidas que suscitaron el descontento del campesinado que constituía las $3 / 4$ partes de la población, y provocaron el desabastecimiento de las ciudades. Los nuevos dirigentes se vieron obligados a suavizar los planes porque consideraban que primero era necesario cambiar la mentalidad de los pequeños propietarios.

Uno de los hechos que va a influir de manera decisiva en la creación de una vía yugoslava al socialismo, fue la ruptura con Moscú en 1948. Las causas del conflicto no surgieron en 1948, sino desde el inicio de la sublevación de los partisanos en 1941. Stalin advirtió a Tito del error de emprender una política revolucionaria en un momento en el que los Aliados luchaban contra los alemanes, y le aconsejó unir sus fuerzas con las de los Četnici del general Draža Mihajlovic, al que tanto Stalin como los Aliados reconocían como único jefe de la lucha armada.

Al terminar la Guerra, Tito no cuestionó la hegemonía soviética, pero a pesar de aceptar la ayuda económica y la llegada de consejeros de la URSS, emprendió una política muy personalista para proteger los intereses de Yugoslavia. Tito había demostrado su independencia durante la guerra y se consideraba un igual ante los Aliados y ante Moscú.

El equilibrio de fuerzas entre los dos bloques, el occidental y el comunista tuvo mucho que ver con la ruptura en 1948. En una conversación que mantuvieron Churchill y Stalin el 4 de octubre de 1944 en Moscú, para valorar el reparto de zonas de influencia, que en la práctica ya se había realizado en función del avance del Ejército soviético, sugirieron un reparto de influencia en el territorio yugoslavo de un $50 \%$. Tito se irritó profundamente 
cuando tuvo conocimiento del acuerdo, pero terminó aceptando la conveniencia de no pertenecer a ningún bloque político, lo que en el futuro supuso una gran ventaja para la reconstrucción del país.

En 1947, Stalin había creado el Cominform con el fin de controlar los partidos comunistas de las nuevas repúblicas socialista y los partidos comunistas más desarrollados de Europa, el francés y el italiano. Tito apoyó la iniciativa, pero mantuvo su postura de realizar una política exterior independiente. Las divergencias entre Tito y Stalin fueron en aumento: el problema de Trieste que Tito reivindicaba, problema que no se solucionaría hasta 1954, el proyecto de establecer una federación balcánica con Bulgaria, el envío de tropas yugoslavas a Albania para fortalecer sus fronteras con Grecia y su apoyo a los comunistas griegos, contrariaron a Stalin que veía con recelo la excesiva independencia de Tito. La tensión explotó en una fecha muy significativa, el 28 de junio de 1948. Stalin subestimó el dominio de Tito sobre el partido comunista yugoslavo y su capacidad para movilizar el sentimiento patriótico, a pesar de que una quinta parte de los miembros del Partido apoyó la decisión del Cominform. Como declaró Tito ante el Comité Central del partido:

«Por mucho que cada uno de nosotros ame a la URSS, la tierra del socialismo, no debemos en ningún caso amar menos a nuestro país, lo cual es también una manera de desarrollar el socialismo".

En Occidente la ruptura fue considerada como una victoria de David sobre Goliat. El temor de un ataque soviético fue mitigado por la situación internacional, pues la URSS no estaba en condiciones de provocar un conflicto con Occidente, y Yugoslavia, por su situación geoestratégica y por su oposición a Moscú, no era algo a lo que renunciase fácilmente los Estados Unidos y Gran Bretaña.

La reconciliación con Moscú no llegaría hasta 1955, cuando Kruchev visitó Belgrado y reconoció la pluralidad de vías nacionales al socialismo. Fue entonces cuando Tito inició el proceso de descentralización para hacer el comunismo más soportable, pero para demostrar su fidelidad a las autoridades soviéticas, emprendió una represión contra los líderes comunistas revisionistas, como fue el caso de uno de los más cercanos a Tito, Milovan Djilas, que fue el primero en desenmascarar los equívocos de la nueva clase titoista que él mismo contribuyó a llevar al poder, cuando en el fervor de la lucha revolucionaria, escribía que:

«sin Stalin ni siquiera el sol habria podido resplandecer como lo hacia».

El acercamiento de Tito a la URSS decepcionó a Occidente por lo que consideraba una radicalización de su política. No hay que olvidar que, aunque la revolución húngara de 1956 debe mucho a la disidencia de Tito, éste 
consideró que los objetivos de los insurgentes iban más allá de lo que podía aceptar para Yugoslavia, y dio su aprobación para la invasión soviética. Después de la detención del dirigente húngaro Imre Nagy, al que Tito había concedido asilo en la Embajada yugoslava en Budapest, las relaciones con la URSS volvieron a enfriarse $y$, aunque hubo períodos de acercamiento, nunca fueron del todo amistosas.

La ayuda económica occidental permitió la reconstrucción del país y el inicio de la llamada Tercera vía o modelo yugoslavo hacia el socialismo mediante un nuevo sistema económico: la autogestión, y una política exterior alejada de los dos bloques: el movimiento de países no alineados.

Después de la ruptura con la URSS, en contra de lo que era de esperar, se aceleró la colectivización de la agricultura y la continuación de los planes. Pero los resultados fueron muy negativos y se incrementó el absentismo laboral de una población en su mayoría campesina, que prefería trabajar en las explotaciones familiares para compensar su bajo nivel adquisitivo.

Esta fase estalinista reflejaba un claro síntoma de falta de identidad del comunismo yugoslavo y no podía durar mucho tiempo. Tito comprendió que era necesario reforzar la independencia de Yugoslavia a través de un verdadero socialismo democrático y de un nuevo sistema económico de economía de mercado, la autogestión.

La idea de que los obreros se organizaran por sí mismos quedó recogida en la Ley de 27 de junio de 1950, en la que se especificaba que la propiedad de los medios de producción no pertenecía ni a particulares ni al Estado, sino a toda la sociedad. Se organizaron los consejos obreros, los comités administrativos y de dirección. Sin embargo, no se modificó el carácter monolítico del partido, y por lo tanto, la autogestión no fue algo conquistado por los trabajadores, sino que fue concedida por el partido.

La ausencia de sindicatos independientes, el desigual reparto de los fondos de inversión entre empresarios y obreros, las ventajas sociales de los primeros, la escasa participación de las bases en la toma de decisiones de los consejos, las diferencias de desarrollo entre las repúblicas, hicieron que los resultados de esta primera fase de la autogestión fuesen muy limitados y tuvieran más importancia ideológica que económica.

La verdadera vía yugoslava al socialismo empieza a partir de 1961. Los dirigentes liberales trataron de dar un nuevo impulso a la economía mediante la liberalización de los precios, ampliación de competencias de los consejos obreros en la distribución de las inversiones y un sistema de créditos en el que los bancos remplazarían progresivamente la autoridad del Estado. Sin embargo, para que la reforma fuese eficaz se tenía que poner fin al control del partido sobre la economía. La paradoja de Yugoslavia, como en muchos regímenes de carácter autoritario, es que coexistían las estructuras autoritarias y una cierta descentralización. $Y$ mientras que los dirigentes de 
las repúblicas más desarrolladas eran partidarios de mantener la economía de mercado, los conservadores reclamaban una mayor centralización. Los enfrentamientos entre unos y otros despertaron los antagonismos entre los serbios que no querían perder los beneficios del reparto a nivel federal, y los croatas y los eslovenos que no lo aceptaban y reclamaban mayor autonomía política.

Las diferentes reformas que se pusieron en marcha en la Yugoslavia de Tito, unas veces favoreciendo la planificación y otras la economía de mercado, no resolvieron las reivindicaciones nacionalistas. A ello hay que añadir la crisis mundial de 1973, que afectaría a las exportaciones, la deuda externa y al aumento del desempleo. Baste señalar que entre 1958 y 1969 hubo más de 2.000 huelgas por conflictos entre los sindicatos oficiales y los trabajadores. Pero como la ideología oficial las consideraba como una vergüenza política, solían terminar a las 24 horas después de que los dirigentes de las empresas aceptaran a las peticiones de los trabajadores.

La ambigüedad de la autogestión reside en su propia definición: asegurar en los consejos ios intereses de los trabajadores. Pero como las decisiones quedaban en manos del partido, implícitamente se reconocía que la clase trabajadora era incapaz de querer algo por sí misma.

No puede negarse que la autogestión ayudó a la reconstrucción del país, y que se mejoraron los derechos de los trabajadores, sobre todo si se comparan con las demás Repúblicas populares, pero los resultados fueron frágiles y no tuvieron ninguna repercusión en el sistema político. El gobierno federal, debilitado por las reivindicaciones nacionalistas y por la corrupción de las nuevas elites comunistas que habían reemplazado a la generación de los partisanos, vio como desaparecía el ideal del yugoslavismo. Los nuevos líderes, para ascender en el partido y en la administración federal, tenían que formar parte de un grupo nacional y para conseguir el apoyo de su electorado despertaron los viejos antagonismos.

El reconocimiento de las nacionalidades dentro de la ideología del partido reforzó su legitimidad aunque sembraría la semilla de los futuros conflictos. La primera consecuencia de esa política fue el movimiento de países no alineados que proporcionó una kase ideológica en el plano internacional de respeto a las identidades nacionales.

El inicio del movimiento de países no alineados está relacionado con el enfrentamientos entre los dos bloques. Después de la ruptura con Moscú, Yugoslavia supo crear una política exterior independiente. Los países del Tercer mundo que alcanzaron la independencia después de la descolonización, se debatían entre los dos modelos existentes en el mundo en los años cincuenta, el comunismo y el capitalismo. La Conferencia de Bandung en abril de 1954 había condenado el colonialismo. En este contexto, Tito reunió en 1956 a los presidentes de Egipto, Nasser, y de la India, Nehru, para valorar las relaciones entre los dos bloques y adoptar una postura alejada de 
ambos. En 1961, la Conferencia de Belgrado reunió a los dirigentes de 21 países del Tercer mundo, que sentaron las bases del movimiento: condena a las antiguas y nuevas potencias mundiales dominantes, coexistencia pacífica y neutralidad.

El movimiento de países no alineados tuvo una gran repercusión en la política interna del país. Hay un constante movimiento dialéctico entre los acontecimientos internos y su entorno internacional debido a la postura adoptada por Yugoslavia en el nuevo sistema de Estados dominados por las grandes potencias. Sistema federal, autogestión y no alineación están fuertemente unidos en una formulación ideológica coherente que legitimó la política interior y exterior de la Liga de los Comunistas de Yugoslavia.

La política emprendida por Tito como líder de los no alineados tuvo un efecto inesperado, la promoción de los musulmanes, no sólo para mantenerles alejados de las rivalidades entre serbios y croatas, sino también para granjearse la lealtad de una población pro yugoslava. La utilización que Tito hizo de los musulmanes fue una importante baza en su incipiente política de no alineados. Pero incluso ya en noviembre de 1947, Tito supo valorar la importancia de los musulmanes en su política de igualdad y fraternidad. En la votación realizada por la Asamblea general de la ONU en 1947, para la partición de Palestina, tanto la URSS como las nuevas repúblicas socialistas votaron a favor de Israel, mientras que Tito se abstuvo para no irritar a los musulmanes de Bosnia.

Como consecuencia de los nuevos vínculos establecidos con los países del Tercer mundo, especialmente en el mundo árabe, para cubrir los puestos en la carrera diplomática, se tuvo muy en cuenta la confesión musulmana. Pero no hiay que olvidar que esos musulmanes eran ante todo miembros del partido y que hacía tiempo que habían abandonado sus creencias religiosas.

Mientras que el lema de unidad y fraternidad sirvió a los intereses nacionales de los pueblos dentro del marco federal, la unidad fue aceptada como algo inmutable. Pero cuando empezaron a surgir contradicciones en el seno de las repúblicas, la unidad empezó a resquebrajarse.

El año 1966 marcó el inicio de la desintegración del Estado reflejado en dos hechos cruciales. El primero la apertura a los mercados europeos y al turismo, que tendrá una gran repercusión no sólo en la economía, sino también en el comportamiento de los ciudadanos y de sus dirigentes. Las reformas de liberalización en la económica, en los medios intelectuales y en las prácticas religiosas, despertaron las rivalidades entre las repúblicas. Las heridas de la II Guerra mundial nunca se cerraron y, mientras que el fantasma de los Ustaše perseguía a los croatas, los serbios eran acusados de pretender la hegemonía de una Gran Serbia. Tito había presentado una nueva visión de la historia. Algunos acontecimientos fueron realzados y otros ocultados o mitigados para presentar a los comunistas como los únicos libertadores del país. 
El tema prioritario de los debates que se iniciaron en 1966 fue la descentralización. Las repúblicas más ricas, Croacia y Eslovenia, querían recibir más beneficios por los ingresos del turismo que las autoridades federales repartían entre las repúblicas más pobres. Pero las rivalidades económicas eran sólo un reflejo de los problemas étnicos que amenazaban la unidad que Tito había logrado.

En 1964, historiadores nacionalistas croatas ya habían reivindicado la soberanía del Estado de Croacia y la separación oficial del idioma serbocroata. Las reivindicaciones croatas fueron dirigidas por la organización intelectual Matica Hervatska que fue censurada por las autoridades, pero que en 1971 volvería a situarse a la cabeza del movimiento independentista. Por su parte, los serbios reivindicaron el uso del serbio en las zonas de Croacia habitada por mayoría serbia. Pero las diferencias entre serbios y croatas no eran de carácter lingüístico sino político. Aunque el gobierno reprimió cualquier manifestación de nacionalismo, a partir de entonces ya no hizo ninguna referencia a una conciencia nacional yugoslava. En 1964 puede decirse que el yugoslavismo estaba muerto.

El segundo aspecto crucial para el futuro del país fue la caída en desgracia de Alexandr Ranković, Jefe de la Policía secreta, considerado el sucesor de Tito y partidario de un Estado fuertemente centralizado opuesto a la corriente de liberalización y descentralización. En junio de 1966, acusado de abuso de poder y de complot, fue apartado de la esfera política, y la coalición de liberales de Croacia, Eslovenia, y Macedonia encontró libre el camino para poner en marcha la descentralización. La caída de Ranković fue considerada por los serbios como una derrota.

A partir de 1968 destacan cuatro movimientos que van a afectar a la supuesta unidad yugoslava. El primero de ellos fue el caso de los musulmanes. Dentro de la difícil armonía de nacionalidades, a partir de los años sesenta, los musulmanes de Bosnia, que no eran considerados ni como pueblo ni como nacionalidad, empezaron una serie de campañas para ser reconocidos como una nacionalidad diferente a la croata o serbia. En el censo de 1940 , los musulmanes de Bosnia estaban obligados a declararse serbios o croatas. En el de 1948 tenían la opción de declararse como serbio musulmán o croata musulmán. En el de 1953 los musulmanes podían declararse como yugoslavos sin nacionalidad determinada. A partir de 1961, un grupo de académicos bosnios emprendieron campañas por la $\mathrm{M}$ mayúscula, es decir Musulmán, para designar a un miembro de una nación, y musulmán con minúscula, como término que se refiere a una creencia religiosa. En mayo de 1968, el Comité Central del partido comunista Bosnio, proclamó que los Musulmanes eran una nación, derecho que fue aceptado en el censo de 1971, en el que por primera vez aparece el término Musulmán en el sentido de pueblo, y que fue reconocida oficialmente en la Constitución de 1974. Existen varias razones que llevaron a Tito a crear una nueva nación. En primer lugar, porque los Musulmanes harian de contrapeso a las rivalida- 
des entre serbios y Croatas. En segundo lugar porque ese reconocimiento era bueno para su política de no alineados, y por último, porque se debilitaría la identidad religiosa de los propios musulmanes, que en adelante podrían ser comunistas y ateos por doctrina y Musulmanes por nacionalidad. En 1971, cuando Títo nombró a un Musulmán de Bosnia como Primer Ministro de la Federación, un nuevo pueblo había nacido en Yugoslavia.

La lucha del reconocimiento de Musulmán como nacionalidad no fue un movimiento religioso islámico. Por el contrario estuvo dirigida por comunistas musulmanes que deseaban una mayor representación política en la administración federal. En la Yugoslavia de Tito se podía ser Musulmán y al mismo tiempo Testigo de Jehová, caso muy frecuente en el pueblo de Zavidovici en el centro de Bosnia.

El segundo movimiento de desestabilización tuvo como protagonistas a los estudiantes. En el año 1968 se produjeron en Belgrado protestas de los estudiantes en la línea de las que se produjeron en París o Praga. Las reivindicaciones de los estudiantes no eran de carácter nacionalista, sino contra el autoritarismo, la falta de empleos, los privilegios de la clase dirigente, las consecuencias de haber abandonado el verdadero socialismo. Sus reivindicaciones eran una mezcla de ideas igualitarias y de ideas liberales que podrían propagarse a la clase obrera y despertar las rivalidades nacionalistas. Aunque Tito apoyó a los estudiantes y éstos volvieron a las universidades, dos semanas más tarde ordenó una purga de los líderes del partido comunista serbio que fueron reemplazados por antiguos partisanos.

El tercer movimiento de protesta en 1968, fueron las reivindicaciones de los albano-kosovares de la región autónoma de Kosovo-Metohija, Kosmet. Los albaneses de Kosovo siempre habían soñando con la creación de una Gran Albania, como lo fue durante la II Guerra mundial bajo dominio italiano. Pero la consolidación de la Yugoslavia de Tito desvaneció sus esperanzas. Los albaneses de Kosovo fueron considerados como una minoría subordinada a Belgrado e integrados en un Estado que no deseaban.

Tito realizó una política de reconciliación para apaciguar a los albaneses, como permitir el uso de la bandera Albanesa, la creación de una universidad con el sistema educativo albanés en Pristina o un mayor impulso en el desarrollo económico de la región. Pero el resultado fue totalmente lo contrario. En 1970 el control de la provincia estaba en manos de los albano-kosovares, y serbios y montenegrinos empezaron a abandonar la región. A finales de 1974 , la provincia era en todo una República salvo en el nombre.

Los acontecimientos internacionales de 1968 ayudaron a apaciguar las tensiones. La invasión de Checoslovaquia despertó una oleada de patriotismo similar a la de 1948, tanto en la opinión pública como en La Liga de los Comunistas. Tito movilizó de nuevo todas sus energías para mantener unido al país y supo hacer uso del miedo ante un posible ataque de la URSS, para restaurar la posición del régimen que había sido desafiada en ese año 
fatídico por los estudiantes, intelectuales, trabajadores, partidos comunistas locales y nacionalismos. Pero la Unión Soviética no atacó, y los intelectuales yugoslavos reclamaron que Yugoslavia siguiera los pasos de la experiencia checoslovaca. El problema es que Tito no estaba dispuesto a realizar cambios políticos que debilitasen su poder. Descentralización sí, pero sin democracia.

El último, y probablemente el más significativo, de los movimientos de carácter nacionalista fue la Primavera croata. El nacionalismo croata volvió a resurgir en abril de 1971, cuando los estudiantes de Zagreb depusieron al Rector de la Universidad y nombraron a un dirigente estudiantil para reemplazarlo. La Primera Ministra croata, Kučar, y los líderes comunistas croatas apoyaron las protestas de los estudiantes y no hicieron nada para impedir el movimiento, conocido como Primavera croata o Maspokret, movimiento de masas. Aunque inicialmente quedó reducido a los círculos intelectuales, en los meses siguientes la situación fue agravándose y se extendió a los Comités obreros. Los dirigentes protestaban contra la obligación de entregar al gobierno federal las divisas de los trabajadores croatas que regresaban del extranjero, reivindicaban una mayor representación en los organismos oficiales de la Krajina, territorio croata habitado en su mayoría por serbios, y finalmente plantearon abiertamente la cuestión de la independencia de Croacia. Tito consideró que el Maspok se había convertido en un movimiento contrarrevolucionario y pidió a los estudiantes que desconvocasen las huelgas, pero Kučar y Tripalo se unieron a los nacionalistas y alentaron la euforia popular. Tito les amenazó con la propuesta que había recibido de Brejsnev para sofocar el movimiento e insistió en que deberían ser capaces de solucionar los problemas sin su intervención. Ante su negativa, los lideres croatas fueron detenidos el 12 de diciembre, clausuradas las organizaciones estudiantiles y reprimidas las manifestaciones de los trabajadores. El nacionalismo croata fue sofocado, pero no se extinguió. Las purgas que se reailzaron se extendieron a otras Repúblicas para equilibrar la balanza y tuvieron amplias consecuencias en el futuro. Los principales dirigentes de tendencia liberal de Serbia, Eslovenia, Montenegro y Macedonia fueron a su vez apartados del partido por Tito, quien no dudo en neutralizar la oposición nacionalista para restaurar el monopolio de poder del Partido.

Las protestas de los estudiantes serbios, las reivindicaciones de los Musulmanes y de los albano- kosovares y los acontecimientos de la Primavera croata pusieron de manifiesto las desigualdades entre las Repúblicas. En ese contexto, los dirigentes comunistas volvieron a apoyarse en la memoria de la resistencia al fascismo, fuente de legitimación del régimen que había unido a los partisanos de Tito, ya fueran serbios, croatas, montenegrinos, eslovenos, bosnios o macedonios.

Las reformas constitucionales que se efectuaron desde 1946 a 1974, reflejan los cambios socio-económicos que se habían operado en el país. La Constitución de 1974 fue el último intento para reconciliar lo irreconciliable 
mediante una combinación de represión y de derechos. Una de las Constituciones más complicadas y extensas del mundo con sus 406 artículos, trató de perfeccionar el difícil equilibrio entre las diversidades étnicas y económicas y el ideal comunista de unidad socialista. Por un lado se ampliaron las competencias de las repúblicas mediante la descentralización económica, pero no quedó claro quién tenía derecho a la autodeterminación. En la práctica, pese el aparente reparto de poder, la Liga de los Comunistas permaneció exclusivamente en manos de Tito, quien no dudó en reafirmar el papel dirigente del partido, y cuyo poder absoluto quedó reflejado en los 13 artículos dedicados al Presidente. Yugoslavia se convirtió en una confederación de ocho Estados, las dos provincias autónomas con derechos muy similares a los de las Repúblicas y en particular, Kosovo, que vio incrementada su autonomía por el derecho de veto en el parlamento serbio. Se reconoció una mayor participación de los trabajadores en la autogestión, pero despertó poco entusiasmo por el contexto represivo. Sólo Tito y el ejército quedaron para garantizar la unidad. En 1978 el propio Tito confesaba al general Tempo que ya no había Yugoslavia, que ya no había Partido.

La última década del régimen de Tito se caracterizó por una profunda crisis económica y política, y una mezcla de magia y de paternalismo. El malestar serbio fue en aumento por el desarrollo de los acontecimientos en Kosovo, y croatas y eslovenos incrementaron sus críticas por la falta de representación en las decisiones tomadas en Belgrado. Al aumentar los poderes de las Repúblicas, se creó un abismo entre ellas. Rivalidades no sólo de carácter étnico, cultural o religioso, sino de poder, que dieron lugar al nacimiento de burocracias nacionales que se constituyeron en centros rivales de poder.

Poco antes de su muerte, Tito ordenó un cambio constitucional para introducir una presidencia rotativa anual. Con ello reconocía implícitamente que el sistema político que había tratado de establecer, es decir, lo que algunos políticos han definido como el Titismo, en realidad fue una consecuencia del monopolio de la burocracia del partido y de su propia personalidad que se confunde y mezcla con la historia del país. El Titismo no pudo suceder a Tito.

A modo de conclusión puede avanzarse que la revolución comunista no resolvió el problema de las nacionalidades y tampoco el lema de unidad y fraternidad logró que se fundieran en una sola. La sociedad se había estratificado y pluralizado. La autogestión no fue una solución definitiva para la economía y el movimiento de países no alineados no tuvo fuerza suficiente para competir con los bloques comunista y capitalista.

Tito fue un político de gran talento, pero no supo crear formas institucionales duraderas. Su política se fue adaptando a las circunstancias internacionales, mostrando una veces su cara liberal a Occidente de donde venían los créditos, y otras, mostrando una actitud conciliadora con la Unión Soviética, mediante la restricción de exactamente las mismas libertades de 
las cuales presumía en Occidente. Con su muerte el 4 de mayo de 1980, el Titismo perdió su significado y los yugoslavos el líder que les había mantenido unidos. Las fuerzas políticas que habían surgido en los años sesenta en Croacia, Serbia, Bosnia, Macedonia y Eslovenia minaron la estructura del partido. Después de Tito aparecieron los odios escondidos, y los nacionalismos reprimidos fueron alimentados por líderes ambiciosos.

Tito quiso ser el símbolo de puente entre Oriente y Occidente, posición que se ha sugerido fue inspirada por el libro del premio Nóbel de literatura, Ivo Andric, Un puente sobre el Drina, puente tendido sobre abismos que separan religiones y pueblos, pero sobre el que acaba en fundirse y mezclarse la plural Yugoslavia. Es el puente que para los comunistas representaba el lema de unidad y fraternidad. Para Andric, como para muchos otros que creyeron en una nueva vía al socialismo, capaz de superar la historia de los conflictos que habían conformado Yugoslavia, la época en que le tocó vivir, la Yugoslavia de Tito, a pesar de todo, no fue la peor de las soluciones históricas. 